\title{
Combating the Spread of COVID-19, the Challenges Faced and Way forward for the International Community: A Review
}

\author{
Theophilus Pius ${ }^{1}$, Saphurah Nabaasa1, Nicholas Kusiima1, Ejike Daniel Eze ${ }^{2}$, \\ Blessing Jacob Yashim ${ }^{3}$, Ssebuufu Robinson ${ }^{4}$ \\ ${ }^{1}$ Department of Medical Laboratory Sciences, Kampala International University, Bushenyi District, Uganda \\ ${ }^{2}$ Department of Physiology, Kampala International University, Western Campus Bushenyi District, Uganda \\ ${ }^{3}$ Department of Microbiology and Immunology, Kampala International University, Western Campus Bushenyi District, Uganda \\ ${ }^{4}$ Faculty of Clinical Medicine and Dentistry, Kampala International University Bushenyi District, Uganda \\ Email: *piustheophillus@kiu.ac.ug
}

How to cite this paper: Pius, T., Nabaasa, S., Kusiima, N., Eze, E.D., Yashim, B.J. and Robinson, S. (2020) Combating the Spread of COVID-19, the Challenges Faced and Way forward for the International Community: A Review. Open Access Library Journal, 7: e6426.

https://doi.org/10.4236/oalib.1106426

Received: May 14, 2020

Accepted: November 13, 2020

Published: November 16, 2020

Copyright $\odot 2020$ by author(s) and Open Access Library Inc.

This work is licensed under the Creative Commons Attribution International License (CC BY 4.0).

http://creativecommons.org/licenses/by/4.0/

\begin{abstract}
Coronavirus disease (COVID-19) caused by SARS-COV2 has been a great disaster globally; affecting human lives, world economy, social activities, and above all lack of trust among countries of the world. The dreaded disease has about more than 3,713,796 confirmed cases, 263,288 deaths, and 1,341,059 recovered persons in May 2020. The main purpose of this article is to review measures put in place to combat COVID-19, challenges faced, and way forward for the international community. The study reviewed relevant articles on COVID-19 and measures put in place for combating the spread of COVID-19. The inconsistency in the prevention and control of COVID-19 and unwillingness by the people especially, in developing countries such as Africa has hampered the effective implementation of universal control measures to combat the disease. Also, the lack of a universal approved treatment and lack of trust amongst regions of the world to combat the disease have left many countries to struggle for themselves. The earlier report that the COVID-19 is not airborne and the recent report that is airborne has done more harm than good in terms of preventive measures. Another challenge observed is the lack of a complete understanding of the coronavirus by the scientific community. The association of the COVID-19 with 5G network was another distraction and confusion to the international community in combating the disease as people who were supposed to observe control and preventive measures, found themselves protesting and vandalizing the $5 \mathrm{G}$ tower thereby exposing themselves at risk of been infected with coronavirus. There is a need for a consensus on preventive measures and treatment through evidence-based research that will be effective in combating COVID-19 globally.
\end{abstract}


During this global crisis with COVID-19, the international community must decentralize the testing centers to reach out to the rural areas instead of waiting for case reports from such areas. Social network owners should find a way of filtering and controlling information shared during outbreaks and Pandemics in the future.

\section{Subject Areas}

Public Health

\section{Keywords}

Combating Spread of Coronavirus, Challenges, International Community, Way Forward

\section{Introduction}

The COVID-19 first outbroke in Wuhan city China in the year 2019 which spread was mild at the closing of the year (December, 2019) and the increase spread exponentially with fatalities at the beginning of 2020 [1].

The World Health Organization (WHO) has the declared the outbreak due to COVID-19 in Wuhan China as a global threat and pandemic because of its fast spreading across and fatality across the globe and therefore, ordered for case finding and tracing of all persons suspected to come in contact with a confirmed case [2]. Following the epidemics, recent research shows that the coronavirus is similar to SARS-COV-2 and the Middle East Respiratory Syndrome coronavirus (MERS-COV). The origin of SARS-COV-2 has been speculation since the outbreak as many linked it with bats and pangolins [3].

In China, based on the epidemiologic characteristics observed, everyone was assumed to be susceptible, although there may be risk factors increasing susceptibility to infection. During the early stage of the outbreak in Wuhan, the main strategy focused on preventing the exportation of cases from Wuhan and other priority areas of Hubei Province, and preventing the importation of cases by other provinces; the overall aim was to control the source of infection, block transmission and prevent further spread. Even as this measure was introduced in Wuhan which has helped a lot in combating the spread of the virus, it is clear that the virus finally has spread globally [4]. Though public health experts recommend large-scale implementation of high-quality, non-pharmaceutical public health measures. These measures as recommended must fully incorporate immediate case detection and isolation, thorough close contact tracing and monitoring/quarantine, and direct population/community engagement. Despites the recommendation, a lack of initial cooperation among people from developing countries especially Africa has slowed down efforts of government and health agencies in controlling the spread thereby, leading to continuous increase in COVID-19 cases in African continent [5]. 
In South Korea, the first case was identified on January 20, 2020 followed by the detection of one to two cases on average in the later days. However, the number of confirmed cases of SARS-CoV-2 infection started to increase rapidly on February 19, 2020 with a total of 6284 confirmed COVID-19 cases including 42 deaths as reported by Korea Centers for Disease Control and Prevention (KCDC) (KCDC, 2020). Following increase of cases since the index case, the COVID-19 response team called for implementation of wide array of social distancing measures to rapidly contain the outbreak in Korea which mitigates the morbidity and mortality impact of the disease, and to stem the number of case exportations to other nations [6].

The control of COVID-19 has been very challenging because of its similar clinical manifestation with other respiratory infections such as the flu, common cold, and the fact that many appeared to be asymptomatic for many days even after been exposed to the SARS-COV-2 virus [7]. A study of systematic review and meta-analysis reported no sufficient evidence of the N95 mask giving protection against viruses and this might reasons why many health workers both in developed and developing countries still tested positive with COVID-19 despite the use of the N95 mask [8]. The transmission of the virus has earlier been reported to be through coming in contact with infected fluid and droplets released through coughing and sneezing by an infected person or being closed to and infected persons; another transmission mode was indicated to be through a handshake with an infected person and touching contaminated surfaces which will eventually lead transferring the virus particles to the eyes or nose to set in infection [9]. Despite the awareness of COVID-19 spread, the developing countries especially, Africa find it hard to cope with lockdown or stay at home strategy as most of them depend on the daily income to survive.

\section{Objective of the Study}

The main purpose of this study was to look at combating of COVID-19, the challenges faced by the international community and way forward for future outbreaks and Pandemics.

\section{Methods}

This study reviewed published relevant articles on COVID-19 from across the globe; those which are not published in English Language were not included in the review. All relevant articles were analyzed and summarized specifically to look at the trends of the virus spread and how the international community work towards combating the spread of the virus and challenges faced in the course of implementing public health measures. The articles reviewed were cited with Mendeley reference software.

\section{Challenges Faced in Combating COVID-19}

This study observed variation in information sharing towards combating COVID-19 to be a stumbling block in curtailing its spread; many were told that 
alcohol can cure or prevent the disease thereby, leading many people abusing alcohol which eventually led to their early grave.

The lack of truth about the presence of SARS-COV-2 in many developed countries such as Korea, Singapore, Italy, Spain, the UK, the United States of America, and Thailand has harmed than good to other parts of the world that were yet to confirm a case. For example, people who traveled and are still in countries with confirmed cases during the outbreak should have been restricted from traveling and screening done on them before allowing people to travel back to their destinations. In Eastern Africa and Uganda to be specific, most of the initial confirmed COVID-19 cases were from outside the country and the same with West African, Northern Africa, Southern Africa, and Central Africa. Although, the use of a medical mask was recommended, no evidence has shown that the mask was manufacture for viral prevention. The medical mask itself was purposely to prevent contamination during medical procedures that may expose the patients to infection from normal microbial flora or potential pathogens and its recommendation has misled many that it protects them from SARS-COV-2 the causative agent of COVID-19. This misleading has brought a rumor in various media across the world that the medical mask should not be used because it was tested and discovered it has coronavirus.

Africa being a developing continent where many people live below one dollar a day has difficulty in putting the lockdown directive into practice as many people were resistant to the government directives and this led many being exposed to the COVID-19 viruses; country like Nigeria have a challenge in making the people abide with the lockdown as residents and religious leaders seen holding religion services and this led to arrest of the leaders also, a riot by the followers. Tanzania in East Africa did not ban religious gatherings until April 2020 when cases of COVID-19 begin to increase in numbers.

Social media though contributed to the sharing of information on prevention and control of COVID-19, misleading information from social media has also hampered the fight against combating the coronavirus spread. The rumour linking COVID-19 spreading and 5G network has been a very big challenge and a setback to public health effort towards combating COVID-19 [10]; the fake news which has spread through social media has led to destruction of $5 \mathrm{G}$ network tower in most developed country such as the United States of America (USA) and United Kingdom (UK) [11]. The linking of COVID-19 and 5G network was a distraction to the international which instead of observing preventive measures put in place, people went on protest, attack and abuse of engineers who have connection with 5 Gnetwork and this led to continuous spreading amongst the people. This theory linking COVID-19 and 5G network also known as the conspiracy theory was traced by researchers to a statement made by a Belgium Doctor in January 2020 where he raised concern about health problems of COVID-19 and the 5G network [12].

The COVID-19 Pandemic has hit the world hard with many cases and fatali- 
ties recorded; and the magnitude of how far it will continue is scary. Many treatments claims have been in circulation ranging from preexisting drugs used for other diseases such as Hydroxy-chloroquine, antiviral (lopinavir/ritonavir, favipiravir and remdesivir), nitazoxanide, ivermectin drugs and herbal medicine across the world [13]. The lack of consensus of the treatment claims by different health agencies around the world has hamper the progress and effort of arriving at a universal medication for COVID-19 [14]. Also, there is lack of trust between regions of the world in respect to where the COVID-19 medicine should come from irrespective of whether it is herbal or synthetic medication. Recent claim of cure to COVID-19 by the led Madagascar government has received no support by world health organization (WHO) though; some African countries extended their interest to try the Madagascar herbal medicine, the proof of cure has not been reported by other African countries yet. Another treatment claims was the transfusion of convalescent plasma (plasma collected from a recovered patient from COVID-19) to treat infected COVID-19 patients [15].

\section{Way Forward}

1) The world health organization (WHO) in conjunction with the ministries of health of all countries should ensure the availability of testing kits that is cost-effective and accessible to all people. The set-up of one or just a few testing centers has slowed down case tracing and findings of contact of COVID-19 persons.

2) The scientific community must rise and make available an evidence base mask that is proven to protect against the virus that is transmissible through the respiratory system.

3) The WHO should find a way of passing information to the rural community and vulnerable people directly and timely to pass important communication or counter misleading information for effective prevention and control measures.

4) Bringing COVID-19 testing laboratories closer to the people by creating more Testing centers across countries affected with the pandemic will lead to a quick diagnosis and confirmation of cases across the country.

5) Alcohol made sanitizers should be made available in all public places entrances in industries, banks, hospitals, schools, and offices to aid in combating COVID-19 and other infectious diseases that are highly contagious.

6) Social media operators should be engaged in controlling misleading information about COVID-19 that will endanger the lives of the public and affect the fight against the spread of coronavirus.

\section{Conclusion}

The COVID-19 has been a great public health disaster of 2020 with exponential increases in cases and fatalities across the world. However, measures put in place by many countries affected by the pandemic have helped in slowing down the 
spread of COVID-19. Though information is limited on the novel coronavirus and no specific proven cure or vaccine has been made available, public health measures should continue to be used through the guidance of religious and community leaders to win this war of bringing COVID-19 to an end. Social media should be engaged in confirming, controlling the sharing of important information in regards to COVID-19 and future pandemics or outbreaks to avoid misinformation reaching the public.

\section{Funding}

This study review has been personal motivation from the authors towards contributing to body of knowledge in regards to combating the COVID-19 pandemics and has no funding or grant concerning its development.

\section{Acknowledgements}

The authors acknowledged the Management of Kampala International University Western Campus, Uganda for making the environment conducive to come up with this work especially, making internet access for use. The authors also, appreciate the Center for Disease Control (CDC) Uganda, World Health Organization (WHO), and researchers around the globe towards making available information on COVID-19.

\section{Conflicts of Interest}

The authors' contribution towards reviewing the COVID-19 situations has not involved any human or its biological samples of any kind and therefore, has declared that no competing interest exists with regards to the publication of this manuscript.

\section{References}

[1] Fedson, D.S., Opal, S.M. and Rordam, M. (2020) Hiding in Plain Sight: An Approach to Treating Patients with Severe COVID-19 Infection. mBio, 11, e00398-20. https://doi.org/10.1128/mBio.00398-20

[2] WHO (2020) Global Surveillance for COVID-19 Caused by Human Infection with COVID-19 Virus. 1-4.

[3] Meng, L., Hua, F. and Bian, Z. (2020) Coronavirus Disease 2019 (COVID-19): Emerging and Future Challenges for Dental and Oral Medicine. Journal of Dental Research, 99, 481-487. https://doi.org/10.1177/0022034520914246

[4] Aylward, B., Liang, W., Dong, X., Eckmanns, T., Fisher, D., Ihekweazu, C., Lane, C., Lee, J.K., Leung, G., Haiying, J.L., Liu, H., Pshenichnaya, N., Semenov, N., Takahashi, H., Van Kerkhove, M., Guangfa, B.G., Wang, G., Wu, F., Wu, Z., Wu, Z., Xing, J., Yuen, K.Y., Zhou, W., Zhang, Y. and Zhou, L. (2020) Report of the WHO-China Joint Mission on Coronavirus Disease 2019 (COVID-19). 16-24.

https://www.who.int/docs/default-source/coronaviruse/who-china-joint-mission-o n-covid-19-final-report.pdf

[5] Kasozi, K.I., Mujinya, R., Bogere, P., Ekou, J., Zirintunda, G., Ahimbisibwe, S., Matama, K., Ninsiima, H.I., Echoru, I., Ayikobua, S.G., Musinguzi, P.S., Muyinda, R., 
Ssempijja, F., Matovu, H., MacLead, E., Euan, A. and Welburn, S.C. (2020) Pandemic Panic and Anxiety in Developing Countries. Embracing One Health Offers Practical Strategies in Management of COVID-19 for Africa. The Pan African Medical Journal, 35, 3.

[6] Shim, E., Tariq, A., Choi, W., Lee, Y. and Chowell, G. (2020) Transmission Potential and Severity of COVID-19 in South Korea. International Journal of Infectious Diseases, 93, 339-344. https://doi.org/10.1016/j.ijid.2020.03.031

[7] Unhale, S.S., Ansar, Q.B., Sanap, S., Thakhre, S. and Wadatkar, S. (2020) A Review on Corona Virus (COVID-19). World Journal of Pharmaceutical and Life Sciences, 6, 109-115.

[8] Offeddu, V., Yung, C.F., Low, M.S.F. and Tam, C.C. (2017) Effectiveness of Masks and Respirators against Respiratory Infections in Healthcare Workers: A Systematic Review and Meta-Analysis. Clinical Infectious Diseases, 65, 1934-1942. https://doi.org/10.1093/cid/cix681

[9] Rahman, S. and Bahar, T. (2020) COVID-19: The New Threat. International Journal of Infection, 7, e102184. https://doi.org/10.5812/iji.102184

[10] Ahmed, W. and Vidal-alaball, J. (2020) COVID-19 and the 5G Conspiracy Theory: Social Network Analysis of Twitter Data. Journal of Medical Internet Research, 22, e19458. https://doi.org/10.2196/22374

[11] Satariano, A. and Alba, D. (2020) Burning Cell Towers out of Baseless Fear They Spread the Virus. The New York Times Morning Briefing. https://www.nytimes.com/2020/04/10/technology/coronavirus-5g-uk.html/

[12] Downing, J., Ahmed, W. and Vidal-alaball, J. (2020) Battling Fake News and (In)Security during COVID-19.

[13] Gautreta, L.P., Lagiera, J.-C., Parolaa, P., Hoanga, V.T., Meddeba, V., Mailhea, M., Doudiera, B., Courjone, J., Giordanengoh, V., Vieiraa, E.E., Duponta, H.T., Honoréi, S., Colsona, P., Chabrièrea, D.R., Scolaa, B.L., Rolaina, J.-M. and Brouquia, P. (2020) Hydroxychloroquine and Azithromycin as a Treatment of COVID-19: Results of an Open-Label Non-Randomized Clinical Trial. International Journal of Antimicrobial Agents, 56, Article ID: 105949.

[14] Simsek Yavuz, S. and Ünal, S. (2020) Antiviral Treatment of COVID-19. Turkish Journal of Medical Sciences, 50, 611-619. https://doi.org/10.3906/sag-2004-145

[15] Bloch, E.M., Bailey, J.A. and Tobian, A.A.R. (2020) Deployment of Convalescent Plasma for the Prevention and Treatment of COVID-19. Journal of Clinical Investigation, 130, 2757-2765. 